\title{
Climate Crisis Adaptation - Strategies Towards Resilience - from Different Perspectives and in Comparable Conditions as Starting Points for Urban and Architectural Interventions in Milan and Vienna
}

\author{
Silja TILLNER, Architects Tillner \& Willinger, Austria, Polimi, Italy
}

\begin{abstract}
Most large cities worldwide have recently experienced the dramatic effects of the climate crisis. The focus of this paper lies on illustrating different scenarios for cities on a 1.5-degree pathway, which means a $50-55 \%$ net emissions reduction by 2030 versus 2010 levels. The two selected cities, Milan and Vienna, are comparable in size and social set-up. The commonalities form the base for a comparison and for the definition of the next steps. Current strategies, urban and architectural interventions, future initiatives in both cities will be compared with more innovative ones that go beyond the status quo in which economic and private interests outweigh public ones. The COVID-19 outbreak and the severe lockdown in Vienna and Milan have acted as game-changers. Closed streets and reduced driving lanes to facilitate pedestrian and cycle movement became possible. The question is how many of these interventions remain or if business as usual returns. Although the negative health consequences of constant exposure to air pollution, especially for the lungs, were known before, addressing them has now gained additional weight. Governments are well-advised to use the strategies they developed for fighting COVID-19 also for making serious efforts in fighting climate change.
\end{abstract}

\section{Keywords}

Climate Crisis, Resilience, Best-Practice Urban Design, Public Space post-Covid-19

\section{International Context}

\subsection{Cities on a 1.5-degree pathway}

Most large cities worldwide have recently experienced the dramatic effects of the climate crisis. The focus of this paper lies on illustrating different scenarios for cities on a 1.5-degree pathway, which means a $50-55 \%$ net emissions reduction by 2030 versus 2010 levels. The necessary investments for reaching that goal will most likely not deliver positive economic returns. Therefore, regulatory incentives are necessary. Five major business, economic, and societal shifts would underlie a transition to a 1.5-degree pathway:

1. Industry

2. Transport

3. Power

4. Buildings

5. Avoided Deforestation \& Agriculture 
Depending on the economic, R\&D, cultural, livability and environmental backgrounds of cities, best defined by their position on the Global Power City Index (GPCI), different conditions arise as starting points for potential interventions.

\subsection{Environmental strategies in two cities in comparison}

The two selected cities, Milan and Vienna, are comparable in size and social set-up. In the $2019 \mathrm{GPCl}$, Northern European and Australian cities received high environmental scores. Vienna scored \# 21 in the comprehensive ranking; Milan was \# 36. Obviously, the COVID-19 crisis is not yet factored into the 2019 report. Other cities with high scores and positive developments in the environmental sector will be referenced in this paper. The commonalities of comparable backgrounds form the base not only for a useful comparison, but also for the definition of the next steps that can be developed further, leading to implementation measures that go far beyond current initiatives.

Current strategies and activities in both cities will serve as groundwork with regard to their applicability elsewhere. Urban and architectural interventions will be researched, evaluated, and exchanged to share knowledge. A strategy consisting of guidelines applicable in both cities will be formulated and used as a foundation for the development of several test cases. Current and future initiatives in both cities will be evaluated and augmented along with more innovative ones that go beyond the status quo, which always tries to strike a balance between economic, private, and public interests. This was not a level playing field in the past, since economic and private interests outweigh public ones, e.g., in traffic-calming aspects. In Vienna, it is a severe lack of green spaces in the densely built-up inner districts; in Milan it is high pollution levels that negatively affect the population. While it would be possible to improve the situation, politicians are not willing to risk the anger of the businesses, the powerful automotive clubs and the drivers in general, who are much more influential and vocal than the pedestrians and cyclists.

\section{Background and Status Quo}

\subsection{Linkage of Environmental and Economic Crisis in Recent Decades}

In the last seven decades, the focus of governments has lain on stimulating continuous economic growth for the sake of job creation and social security, while concerns for the environment were relegated to the background. Brief phases of reconsideration were caused by the oil crisis in the 1970s and the finance crisis in 2009, which led to more austerity and inadvertently helped the environment. As soon as the crisis was overcome, economic growth once again dominated politicians' agendas and the budgets of their respective ministries.

This has changed considerably for several reasons. Over the course of the last five years, cities have been experiencing dramatic effects of the climate crisis. The refugee crisis demonstrated that unbearable living situations drive people to risk their lives just to save themselves and their families. Although the refugee wave in $\mathbf{2 0 1 5}$ was primarily caused by the war in Syria, the same could occur as a result of the climate crisis.

In August 2018, the New York Times published "Losing Earth: The Decade We Almost Stopped Climate Change," an explicit chronicle of all the ignored warnings based on scientific evidence and the missed opportunities to counteract global heating when it was still comparably easy to do so. While the reader was contemplating why on earth politicians did not take action back then, fires were raging in California; in the summer of 2018 not a single day went by without stories about the fires dominating the front page of the Los Angeles Times. Unfortunately, the year 2020 has not brought relief with regard to fires and the Governor of California attributed the large number of fires to hotter temperatures and less precipitation as a result of the climate crisis.

In Europe the summer of 2018 broke all previous heat records and the numbers of tropical nights surged. The combination of hot summers and mild winters continued into the year 2020. 


\subsection{Recent Change in Attitude - Sense of Urgency - Role Models}

Thinking has changed - Ursula von der Leyen, as the newly elected President of the European Commission, has declared that combating climate change is a major goal for her presidency and the EU. Greta Thunberg has reached the young generation and brought the climate crisis debate to every kitchen table and helped to bring a renewed sense of urgency into the political debates. Regrettably, apart from certain pioneering countries and cities, where prime ministers and mayors chose sustainability for their political agenda, even the enormous publicity of Greta Thunberg did not accelerate the necessary measures and expenditures to combat climate change. Anne Hidalgo won her re-election in Paris based on the promise for a sweeping transformation of Paris into a carbon-neutral city. In October 2020, Jacinda Ardern was re-elected as prime minister in New Zealand with a landslide victory not only on account of her successful overcoming of the pandemic in her country, but also because of her ambitious environmental agenda. Now she plans to use the experiences and the skills she has gained from dealing with the Covid-19 crisis to tackle the climate crisis and the loss of biodiversity. ${ }^{1)}$

\section{- Proposals and actions}

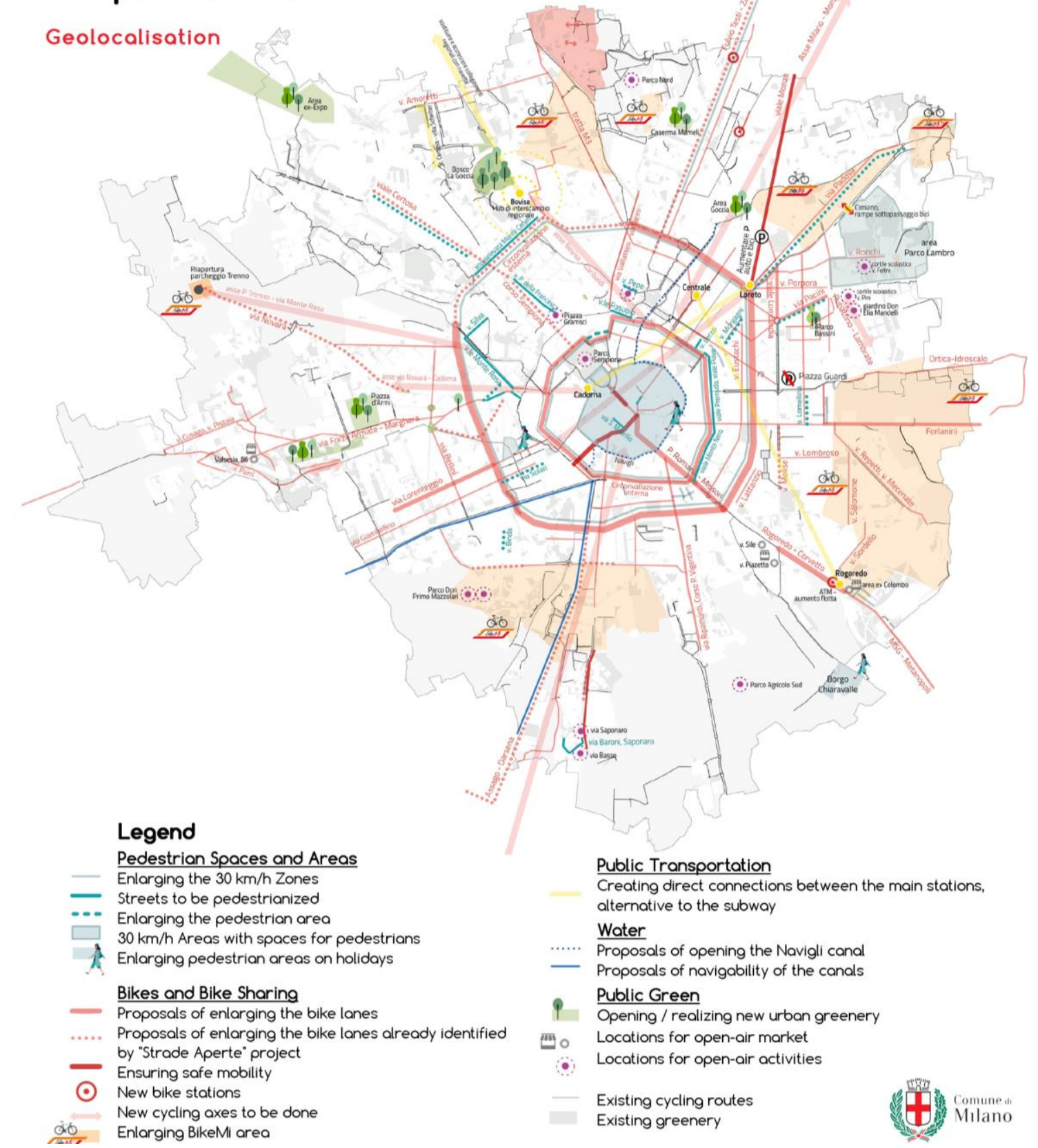

Figure 1 Milan - 2020 strategies for adaptation post Covid-19, Source: Comune di Milano 


\section{Covid-19 and its Impact on Climate Change}

\subsection{The Impact in two cities}

The COVID-19 outbreak and the severe lockdown in Vienna and Milan have acted as game-changers. Suddenly, the streets were traffic-free, and people were circulating only in their immediate vicinity by bike or on foot. Streets and squares were suddenly frequented in much higher numbers due to park closures. The impossible became possible: closed streets and reduced driving lanes to facilitate pedestrian and cycle movement in adequate and safe distances. Will at least some of these interventions remain or will they be reverted and will business as usual return? There are good reasons to hope for permanent change - politically and scientifically. For one, the political landscape has changed and political parties and politicians with an environmental agenda have gained significant support. This goes beyond the classic green parties, as the major parties have also realized the importance of this topic for voters. More important, though, is the new respect for scientists due to COVID-19. The public had to quickly learn how to understand the complicated math curves, e.g., the basic reproduction number, and the genetic and phenotypic structure of the novel COVID-19 virus. New behavioural patterns were adopted rapidly and without many complaints. If it were not for the detrimental economic consequences and the many cases of individual suffering, one could see some benefits. Clearly, lockdowns are not a measure to stop climate change despite the highly visible effects of cleaner air and clear skies, as well as the audible ones resulting from less noise pollution. Since $\mathrm{CO}_{2}$ stays in the atmosphere so long, the main environmental factor, climate change, is not slowed down because of temporarily cleaner air. There is growing scientific evidence of a connection between environmental pollution and the rate of mortality rates due to COVID-19. Environmental factors such as the level of air pollution before the outbreak, especially the level of nitrogen dioxide $\left(\mathrm{NO}_{2}\right)$, and car, plane and industrial emissions all play a role. Another factor is the geography of the regions: Teheran, Northern Italy and Madrid are surrounded by mountains which enclose the area, keeping cold air and the pollutants close to the ground and preventing their dispersal. Although the negative health consequences of constant exposure to air pollution, especially for the lungs, were known before, addressing them has now gained additional weight.

Concluding, governments are well-advised to use the strategies they developed for fighting COVID-19 also for making serious efforts in fighting climate change.

\subsection{Corona Crisis versus Climate Crisis}

In February 2020, the Corona crisis became more and more apparent and started to push the climate crisis into the background. As central and local governments around the world continued to struggle with this new enemy, in the absence of more efficient measures, they all finally resorted to a drastic lockdown as their only resort. For months to follow, the Corona crisis massively impeded our lives and forced us to change our daily habits and routines. Even if people did not fall ill, this contagious virus affected them quite differently. For some, it completely changed their ways of living, working, and earning a livelihood. But as the crisis dragged on and weeks became months, the struggle for economic survival was at the forefront of many people's mind. The concern for the environment became less apparent and politicians no longer felt the pressure of their electorate. Nevertheless, several organizations as well as elected politicians ${ }^{2)}$ realized that all the public spending to combat the economic crisis in the aftermath of the COVID-19 crisis could be tied to either sustainable development or ecological improvements, and therefore have additional benefits, namely reducing $\mathrm{CO}_{2}$ levels and stimulating the green economy.

In his lecture "Sustainability at the heart of COVID-19 recovery," ${ }^{3)}$ Dr Arunabha Ghosh from the UN Committee for Development Policy found clear words to express his concern that action in many 
countries has not been followed by the promises made under the global blueprint for sustainability and that these countries have to take earnest efforts to make the promise of Paris real, because scientific analysis shows that the global community has barely made a dent in the accelerating triple planetary crisis of climate change, nature loss and pollution As the events of this year have demonstrated all too clearly, problems caused by the climate crisis are mounting globally: forest fires, extreme heatwaves, devastating droughts and terrifying floods.

The temporary reduction in emissions during the pandemic lockdowns will have a negligible impact. Without large-scale, structural interventions that permanently wean the world from its addiction to fossil fuels, the rise in temperature will not be reduced.

Humanity's best bet is to minimize the risks and impacts of such crises by putting sustainability at the heart of COVID-19 recovery. New research on COVID-19, for example, suggests that a series of measures to protect the natural world and ecosystem services would cost a mere $2 \%$ of the post-COVID-19 recovery bill. ${ }^{2)}$

\subsection{The Triple Planetary Crisis of Climate, Nature, Pollution and Waste}

Air pollution is the world's single largest environmental health risk. Data from the WHO shows that 9 out of 10 people breathe air containing high levels of pollutants, and that around 7 million people die every year from exposure to polluted air. ${ }^{2)}$

Even before the Covid-19 outbreak, cities with high levels of air pollution were "hotspot" locations for lung diseases, e.g., pneumonia. In 2018, Italian health authorities were concerned by frequent outbreaks of pneumonia in Lombardy caused by water pollution. Having previously suffered from pulmonary diseases results in higher vulnerability to Covid-19. Therefore, one thesis is that the high outbreaks in Lombardy are also a result of earlier illnesses caused by environmental pollution. ${ }^{12)}$ The high pollution levels in Lombardy, Madrid, Tehran, and China, with high concentrations of particulate matter $\mathrm{PM}_{10}$, led to the hypothesis of virus airborne diffusion, based on $\mathrm{PM}_{10}$ as a vector.

While further studies are ongoing, it has become clear that the impacts of COVID-19 have demonstrated that measures for cleaner air can no longer be delayed.

"To address the triple crisis, we must reboot our way of life."2)

\section{Call for Action in the Cities}

\subsection{A chance for change}

Cities are key contributors to climate change and at the same time their residents experience the consequences most directly through the negative impact on urban life due to heat waves.

The COVID-19 pandemic has caused immense suffering and forced everybody to change their way of life - most often at tremendous costs to the society and the economy. In the wake of this catastrophe, there is a chance to transform cities and particularly address environmental pollution in the hardest hit cities to make them more resilient in the future.

Even before COVID-19, as a result of negative impacts due to climate change, not only many European mayors, but also their North American and Asian counterparts declared a state of climate emergency and started to counteract.

As Jeremy Rifkin pointed out, the time for demonstration projects has run out and a mainstream transformation has to take place instead - leading us away from fossil fuels towards a $\mathrm{CO}_{2}$-neutral society.

On one hand, the documentation of best practice examples in different cities is still valid, but cities have to simultaneously start implementing unpopular and quite radical measures if they want to achieve visible results and deliver major emission cuts to reduce warming, on one hand, and mitigate 
its effects, on the other hand. They have to transform the sources of energy provision, apply innovative planning solutions that avoid further sprawl leading to densification, promote a sustainable way of building and renovating the existing building stock, secure the provision of $\mathrm{CO}_{2^{-}}$ neutral public transportation and achieve the change of mobility behavioural patterns. These enormous challenges are difficult to meet alone.

\subsection{Act Together - Cities Combine Strategies under C40}

Cities with similar challenges and comparable resources can therefore support each other and act together. C40 mayors, supported by climate experts, business leaders, youth climate activists and trade unions, have launched the Agenda for a Green and Just Recovery. They published a report that outlines ambitious steps for delivering an equitable and sustainable future for all when recovering from the COVID-19 crisis. Los Angeles Mayor and C40 Chair Eric Garcetti and Giuseppe Sala, the Mayor of Milan, established the C40 Global Mayors COVID-19 Recovery Task Force, bringing together mayors from around the world to create a plan for a green and just recovery. They envision a strong recovery based on the principles of a Global Green New Deal. They plan to lead in building a just transition to an inclusive economy, founded on the swift creation of new and good green jobs, as well as the training and upskilling of workers.

The C40 mayors want to continue to drive greater resilience and equity throughout their cities and society. By providing fundamental public services for all, like delivering safe mass transit and access to clean water, food, sanitation and affordable, healthy housing, they want to ensure the foundation for a fair society and strong economy that can safely weather future shocks. They plan to lead in making cities safer and healthier places by creating " 15 -minute cities," where residents can meet their needs via a short walk or bicycle ride. They will permanently reallocate road space to pedestrians and cyclists, and will invest in nature-based solutions, like parks, green roofs, and permeable pavements, in order to reduce the risks of extreme heat, drought and flooding. Their strategy includes giving public space back to people and nature, reclaiming city streets and guaranteeing clean air, so that cities will become better, healthier, and more sustainable places to live. The ambitious goal is to reduce car use by creating a 15minute city, where everything you need is within a 15-minute walking or cycling radius. ${ }^{4 b)}$ Another new term is "hyper-localism," which describes a new orientation towards the local context as a consequence of lockdown and staying within the neighborhood. ${ }^{4)}$ It has also been interpreted as a revival of the "Biedermeier" period, where staying indoors in familiar surroundings was valued higher than exploring the unknown and visiting foreign places. As positive as the ecological benefits of a smaller radius of movement are, as risky this renewed localism is in strengthening conservative thinking due to a lack of diversity.

\subsection{Paris Courageously Transforms Urban Life Towards Sustainability}

The "15-minute" city concept is based on long-time, previous research into how far city inhabitants are willing to walk to the next public transport stop, shopping and entertainment facilities and cultural locations before they choose to drive. Planners around the globe have been advocating accessibility to services within a 15-minute walk and drawing circles with a radius of 5, 10 and 15 minutes on city maps. The renunciation of the car would improve both living conditions and the environment in the neighbourhood. Professor Carlos Moreno of the Sorbonne in Paris developed the most up-to-date interpretation with the concept of "la ville du quart d'heure" for Paris, in which daily urban necessities work, home, shops, entertainment, education and healthcare are all within a 15-minute reach on foot or by bike. ${ }^{6)}$

He is advising Paris Mayor Anne Hidalgo, who plans to remove 60,000 on-street parking spaces, replace them with green spaces, and install a cycling lane on every street by 2024. During the lockdown, Paris created $50 \mathrm{~km}$ of cycling lanes. 


\subsection{Milan Uses the Momentum of Change to Make a Car-Friendly City More Pedestrian-Friendly}

Having asked itself which society and community it wants to become after the crisis, the City of Milan decided that the objective was not just to return to life as it had been before, but rather preserve some of the positive outcomes of the current development and integrate them with a turn towards environmental consciousness. The city is currently creating 35 kilometres of new bike lanes and pedestrianizing several school streets. Milan is running a 15-minute pilot in Lazzaretto, a densely built-up area around the former hospital, as a scheme for "rethinking the rhythms" of the Lombard capital.

It plans to increase the number of streets with a moderate speed of $30 \mathrm{~km} / \mathrm{h}$, an especially important move for pedestrian safety in a city where drivers like to drive fast! An increase in residential streets where pedestrians and cyclists have priority, and free outside space for bars and restaurants in "Piazze Aperte" ("Open Squares") are measures that will activate public life dramatically. "Strade Aperte" ("Open Streets") is the plan of the Commune to rethink mobility and public spaces in the months to come (as of April 30, 2020) to transform Milan into a more liveable and sustainable city. An array of measures in the public realm should allocate space in the streets and offer it to different user groups and generations. Cycling and walking shall complement public transport and offer an alternative to the private car.

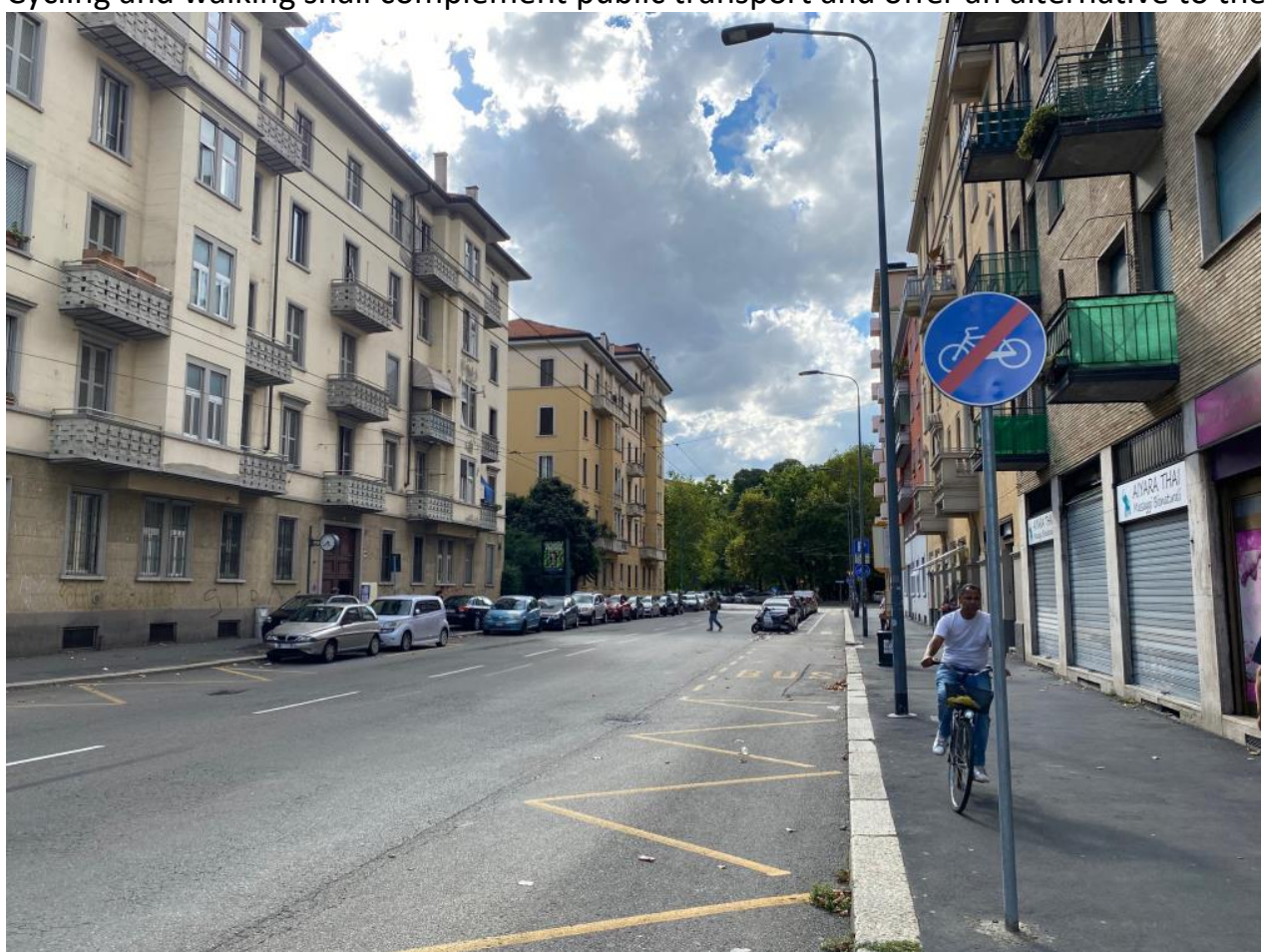

Figure2 Typical Milanese street with ample space for cars - Source Photo: S. Tillner, 09/2020

\section{Time, Space and Services}

The City plans to rethink the times, schedules, and rhythms of the city to distribute the demand for mobility throughout the 24 hours of the day, by applying queue management and heat-mapping tools. Public infrastructures and urban spaces are to be adapted to the new distancing measures, favouring a different use of public space. By ensuring the proximity of essential services within a 15-minute walk to reduce travel, the City wants to seize the moment of discontinuity represented by the health emergency to rethink the organizational methods of services and break established practices and patterns.

\section{Sustainability}

The economic revival shall focus on pursuing the objectives linked to the environmental transition: equity, decarbonization and re-naturalization that lead to climatic resilience and clean energy. The improvement of the air quality has to be seen as a precautionary measure for the policies of health and well-being and consolidate the development of sustainable mobility by drastically increasing individual means of mobility, such as bicycles, scooters and electric motorcycles, including sharing options. The 
return to local production shall be encouraged, the development of newly integrated short supply chains and the management of resources according to the principles of circular economy promoted.

\section{Immediate Actions}

Mobility measures include updated rules and policies on car use (Area C, Area B and parking) depending on actual traffic flows and travel times, favouring people in need and off-peak hours. The "Open Roads Program" shall encourage widespread cycling through the creation of a pedestrian and cycle network starting from the main axes such as San Babila - Corso Buenos Aires - Viale Monza - Sesto Marelli.

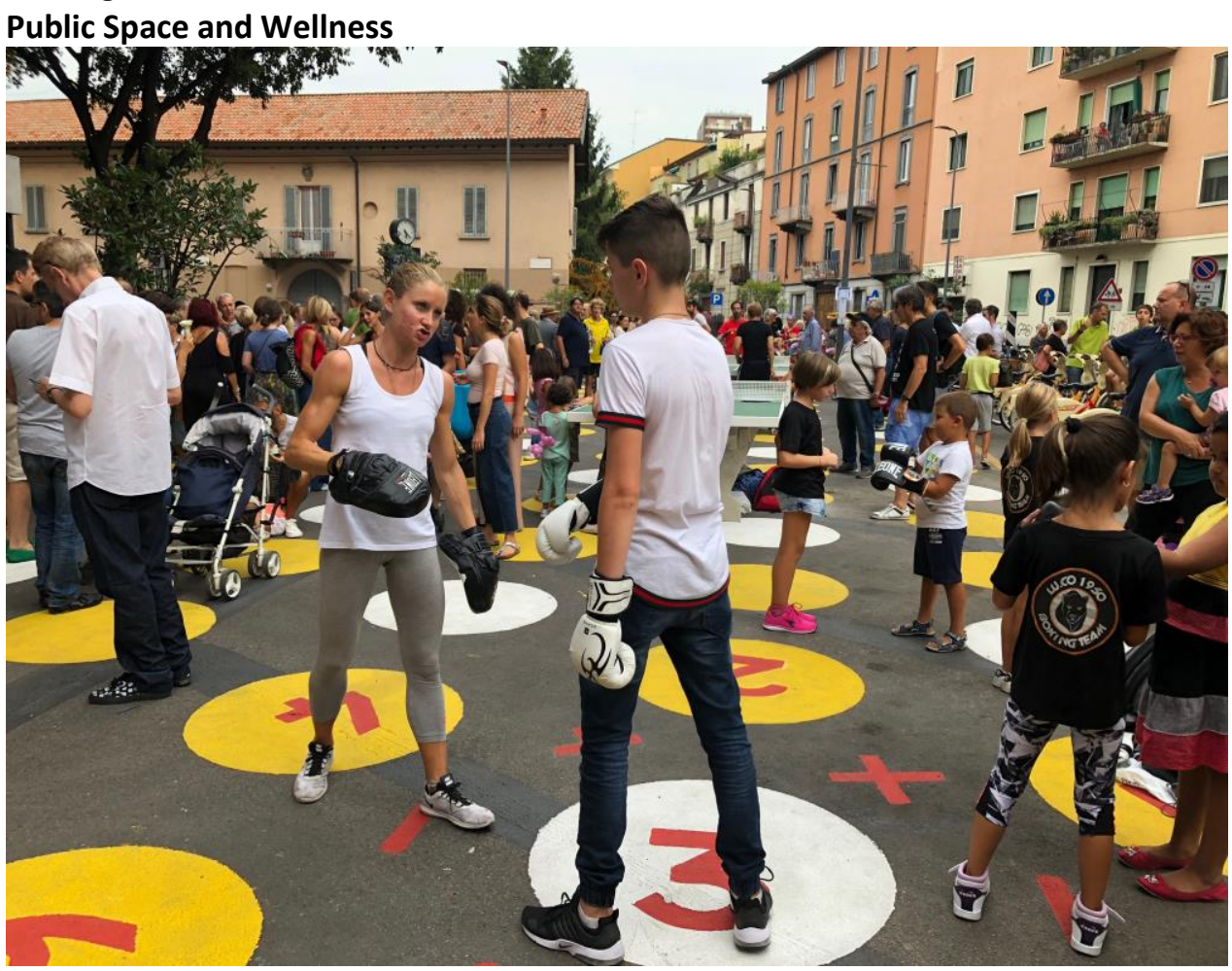

Figure 3 Tactical Urbanism -temporary street-closures activate citizens to use public spaces differently,

Source Photo: S. Tillner 10/2018

The plan is to regain space for physical activities by adapting the sidewalks to the measures of physical distancing, expanding the provision of public space to complement the parks, providing for temporary pedestrianization in the neighbourhoods with few green areas to allow children to play and exercise on so-called "Play Streets." The facilitation of the placement of tables for bars and restaurants on public spaces shall help to recover part of the lost capacity. The use of public space for outdoor cultural and sporting events is encouraged by providing facilities and concessions and simplified procedures. "Piazze Aperte," open squares, shall exist in each district. Tactical urbanism has been a tested and successful intervention in Milan with the aim to restore urban quality and encourage new uses of the streets; in post-COVID-19 times it will facilitate pedestrianization, especially near schools and in neighbourhoods with few green areas, and encourage physical activity and play for children. The maximum speed limit of $30 \mathrm{~km} / \mathrm{h}$ will be introduced in a far-reaching manner in the city, a rule that will also allow the increase of spaces for tables on the edge of the roadway or instead of parking spaces. ${ }^{7}$

\section{C40 Network of Cities - Reinventing Cities .}

\subsection{Meeting the Challenge of Achieving Sustainability and Energy-Efficiency in Existing Buildings}

Milan is part of the C40 network and is one of the cities participating in the Reinventing Cities Competition, ${ }^{8)}$ which aims at enabling demonstration projects that can act as showcases for the future sustainable development of large sites, new development, as well as redevelopment and renovation.

The Palazzine Liberty site is one of seven sites in Milan which are offered for sale or for long-term leasing to participating teams of investors, architects, and environmental experts. The site is particular interesting as it hosts six historic buildings, "Palazzi," of extraordinary architectural value. Energy- 
efficiency, autarky and on-site waste management are all topics of the competition and present an enormous challenge when working within the existing built fabric, especially with architectural monuments. The requirements of energy-efficiency are much easier to fulfil in new buildings than in existing ones, especially when they are protected monuments. Therefore, the focus worldwide has to lie on improving the existing building stock so that buildings can contribute their share to meeting the Paris goals for limiting the global warming to maximum 2 degrees. Buildings of average architectural value are commonly renovated by adding thermal insulation on the outside, thereby changing the appearance in materiality and proportion. This measure cannot be applied to buildings of architectural value; therefore, potential solutions are much more complex and require an integrated interdisciplinary approach. Worldwide, far too few best-practice examples exist; the EU will therefore specially focus on supporting these types of projects in the coming years. In addition to these challenges, the City of Milan expects to make profit from the land-lease and is asking for market-rate prices. In spite of these obstacles, the team Écoquine develoned innovative solutions and was successful in the first round of the competition ${ }^{9)}$

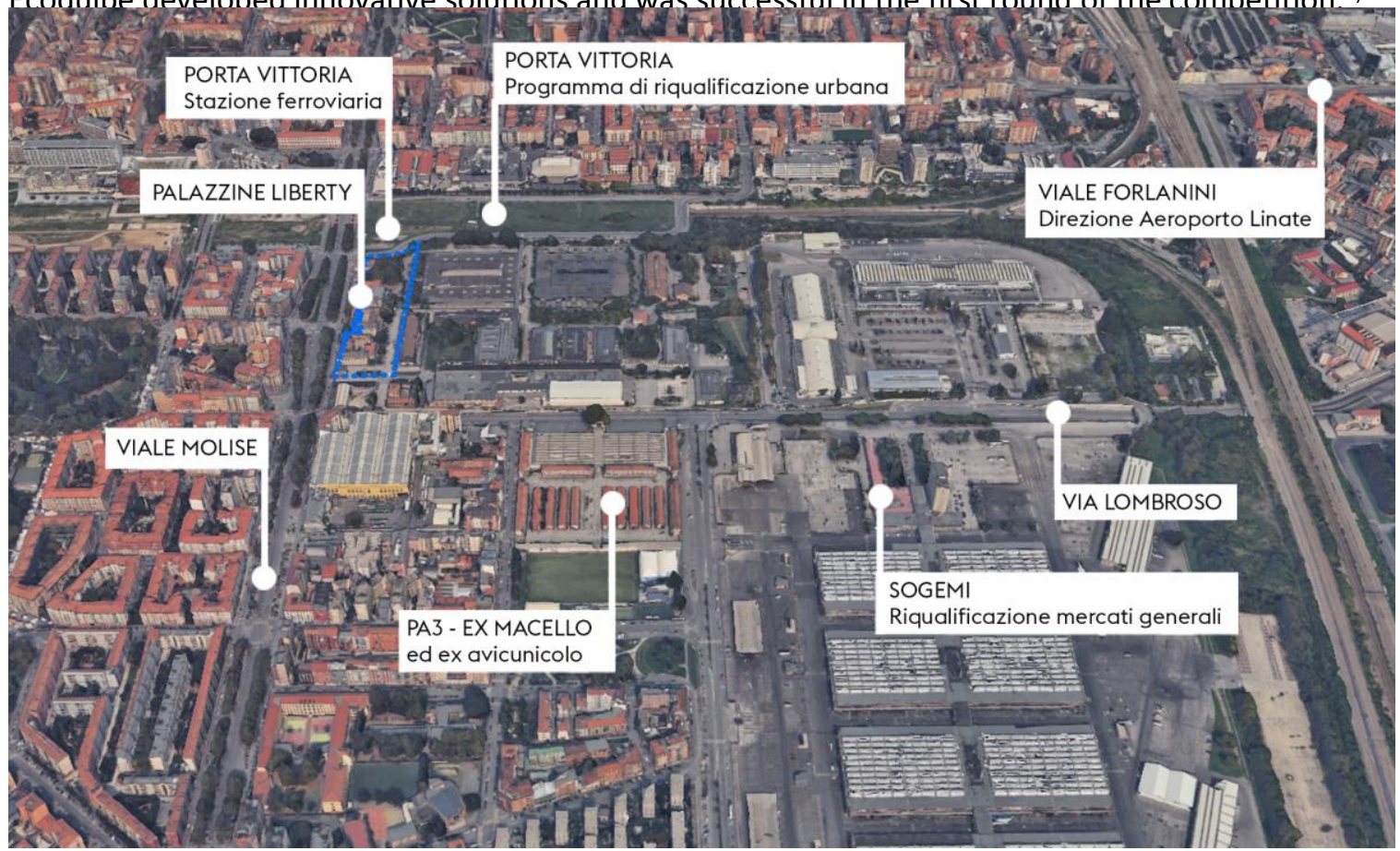

Fig.4: Ex-Macello and Palazzine Liberty Sites near Porta Vittoria, Source: Reinventing Cities Competition ${ }^{8)}$

Sustainable approaches for the challenges of Reinventing Cities: No.1) Energy efficiency and low-carbon energy consumption; no. 2) Life cycle assessment and sustainable construction materials; no. 3) Lowcarbon mobility; no. 4) climate resilience and adaptation; no. 6) sustainable water management; no.8) urban re-vegetation and agriculture. The team proposes an integrated solution for all the challenges mentioned above. In particular, the interaction between the challenges will lead to more effective and synergistic solutions for an optimization of the final result.

The first integrated approach concerns the optimal use of the surface, both ground areas and vertical areas made up of building facades and roofs. The urban surface becomes a means of achieving various objectives in energy, climate resilience and mitigation, water management, urban re-vegetation and agriculture with the following functions: green solutions, solutions for water management, solutions for urban agriculture, solutions for the production of energy from renewable sources and a greening concept for all the surfaces, horizontally and vertically. The set of solutions is then systematized in relation to objectives of resilience and sustainability: microclimate regulation, preservation of habitats and biodiversity, management of rainwater, energy self-sufficiency, food safety and availability of water. In relation to the challenge of urban re-vegetation and agriculture, the proposed approach aims to use both external and internal (underground) surfaces for the production of agricultural products. The use of circular economy systems allows the use of resources collected on site (from rainwater to the by- 
products of primary activities - such as coffee dust and plastic waste - to produce other products.) This approach will also create green jobs and stimulate community engagement around urban gardens.

The second integrated approach concerns energy efficiency and low-carbon energy consumption for urban design and low-carbon mobility. The sustainable energy approach learns from the concept of Sustainable Energy Performances of Urban Morphologies developed by Vettorato in 2011. According to this concept, the three main strategies to transform a neighbourhood in a carbon neutral one are:

- Saving and conserving energy to reduce the energy needs

- Energy efficiency of the infrastructures

- On-site energy production by renewable sources of energy

The three pillars are connected to the urban design aspects through:

a) the modification of the spatial organization by reducing those functions that are energy demanding (i.e., insulation of the buildings, but also reduction of need of transport to reach the site);

b) the modification of the infrastructures: changing those that consume more energy because they are old or damaged or inefficient, with new and more efficient ones (e.g., the heating systems);

c) human behaviours: making users more conscious in relation to their daily roles in consuming less energy by adopting sustainable solutions (from the mean of transport to the selection of proper sources of energy like PV electricity). In summary, the proposals relating to solutions for energy sustainability see:

- Internal insulation of the walls

- Use of greening solutions on the facade also as external insulation

- Internal insulation of roofs

- Renewal of the heating system, replacement of the system from diesel to heat pumps and geothermal probes operated by photovoltaic systems

- Use of heat pumps and geothermal probes also for summer cooling

- Installation of internal fan coils

- Installation of up to $85 \mathrm{kWp}$ of photovoltaic (preserving the architectural integration in the prestigious site)

- Installation of a monitoring and feedback system to users (through displays that make users aware of the use of energy and internal comfort).

The results on building energy uses suggests the potential to reduce the external energy needs of the built site by $53 \%{ }^{10)}$

\subsection{Mobility}

In relation to mobility, the proposal has developed a "reduction" approach to the need for mobility by working on attractors and therefore on the functions allocated on the site, in turn according to the number of users estimated annually and the means available to reach the site. In this way, the impact that the site will have on the generation of $\mathrm{CO}_{2}$ emissions (and primary energy needed) during its operation can be easily calculated. Below is a graph showing the isochrones, or the areas that can be reached in the same period of time by means of walking or cycling.

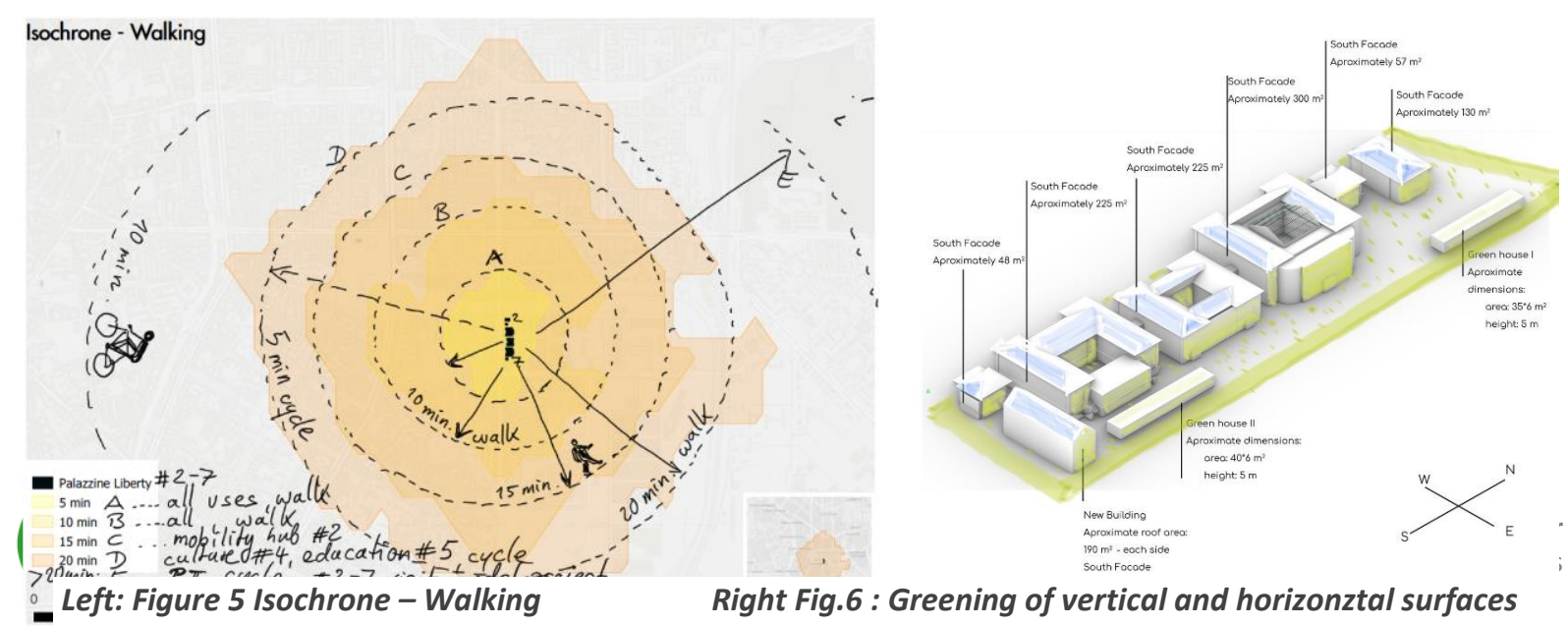




\section{Vienna}

\subsection{Vienna and Milan - similarities}

Milan and Vienna have a lot in common, as they are comparable in size, population, social set-up and geographic position, and experience the impact of climate change with regard to the increase of heat in the city. They benefit from the proximity to surrounding natural resources and attractive open green spaces. Most importantly though, both cities have already invested in environmental issues and want to become carbon neutral.

\subsection{Vienna Smart City}

Vienna has integrated all its sustainability goals into the Smart City Concept and has been showcased as one of the most advanced "Smart Cities" and has adhered to its principles for a decade, leading to tangible results, such as the recurring title "most liveable city of the World" by The Economist, the Mercer Study, etc.

Smart City Wien defines the development of a city that assigns priority to, and interlinks the issues of energy, mobility, buildings, and infrastructure. ${ }^{13)}$

In this, the following premises apply:

- $\quad$ radical resource preservation

- development and productive use of innovations/new technologies

- $\quad$ high and socially balanced quality of living

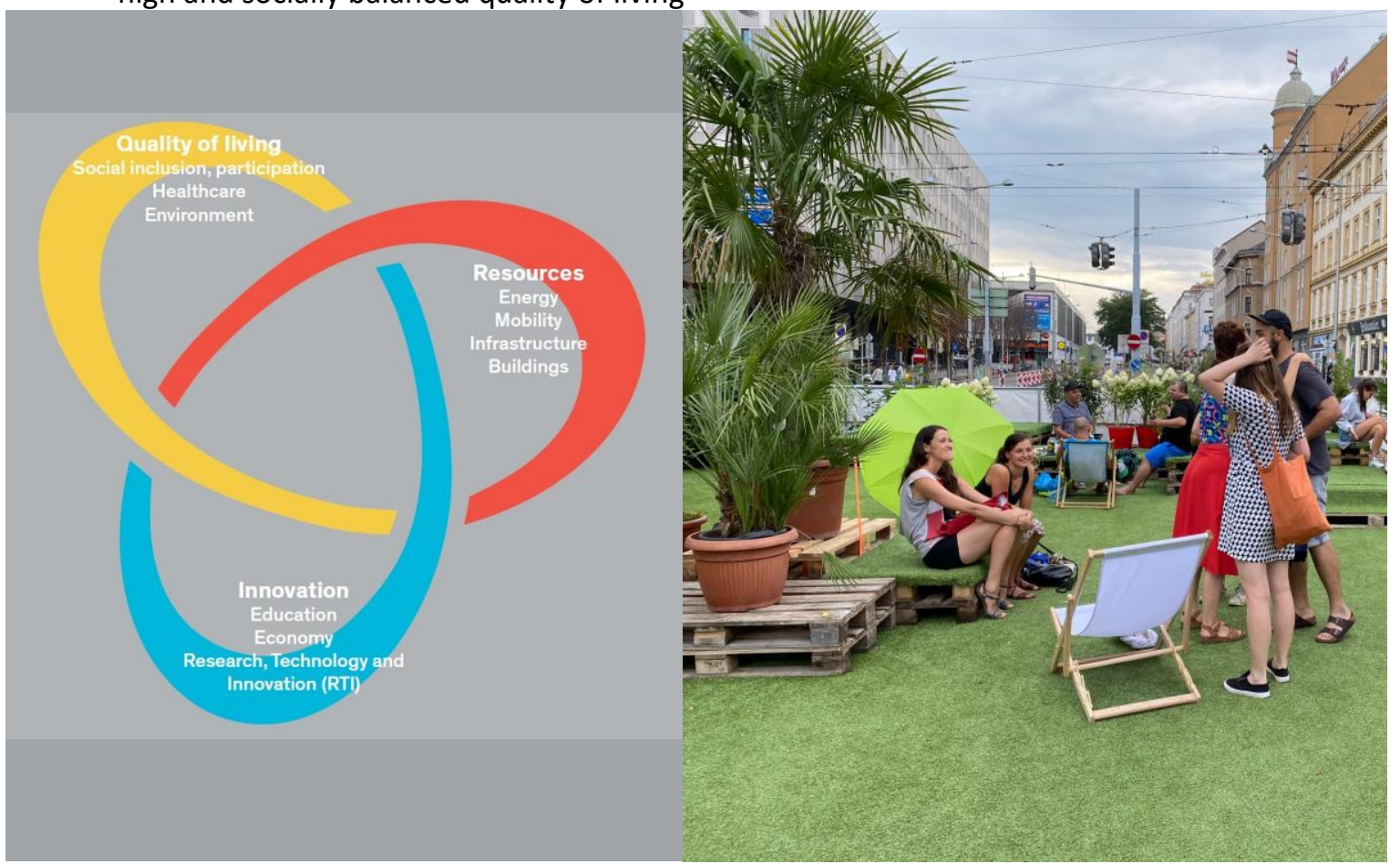

Fig.7 Left: Smart City Wien Logo, Right: Pop-up Lawn and Pool on the Gürtel highway, S.Tillner 08/2020

This is to safeguard the city's ability to withstand future challenges in a comprehensive fashion. The elementary trait of Smart City Wien lies in the holistic approach pursued, which comprises novel mechanisms of action and co-ordination in politics and administration, as well as a wider leeway of action assigned to citizens. In 2020, Vienna is the city with the highest quality of life and life satisfaction in Europe.

\section{Social inclusion:}

Vienna is a city of diversity with affordable housing for all income groups and an attractive living environment and plenty of green space.

\section{Health:}

The city ensures healthcare provision of the highest standard, with outpatient treatment given preference over hospital admission: care is to be provided in structures close to patient's home for as long as possible. 


\section{Environment:}

The percentage share of green space is to be maintained at $50 \%$ up until 2030 by safeguarding of recreation areas.

\section{Resources: Mobility Concept}

Priority is given to environment-friendly modes of transport

The modal split in Vienna is: $20 \%$ motorized traffic, $40 \%$ pedestrians/cyclists, $40 \%$ public transport

The early completion of the U2 underground/metro link before opening new living quarters in the Seestadt assures the use of public transport from day one after moving in of new residents.

Walkability and cyclability are key criteria for the layout of public spaces.

The obligation to build safe and spacious bike parking in each building facilitates the daily use of the bicycle. Reduced parking provision on streets and garages and communal garages for equidistance of car \& public transport make car usage less attractive and create a level playing field for public transport. A local shopping street to meet daily needs "around the corner" also in newly built quarters shall prevent residents from driving for daily necessities.

\section{Quality of Life: City of Diversity}

Jobs, housing, recreation, social infrastructure (local amenities, social provision, healthcare, cultural activities) in the neighbourhood assure work-life balance.

\section{Quality of Life: City of Short Distances}

When local amenities with a mix of segments are in place from the outset as in Seestadt, the 15 minutes city is reality.

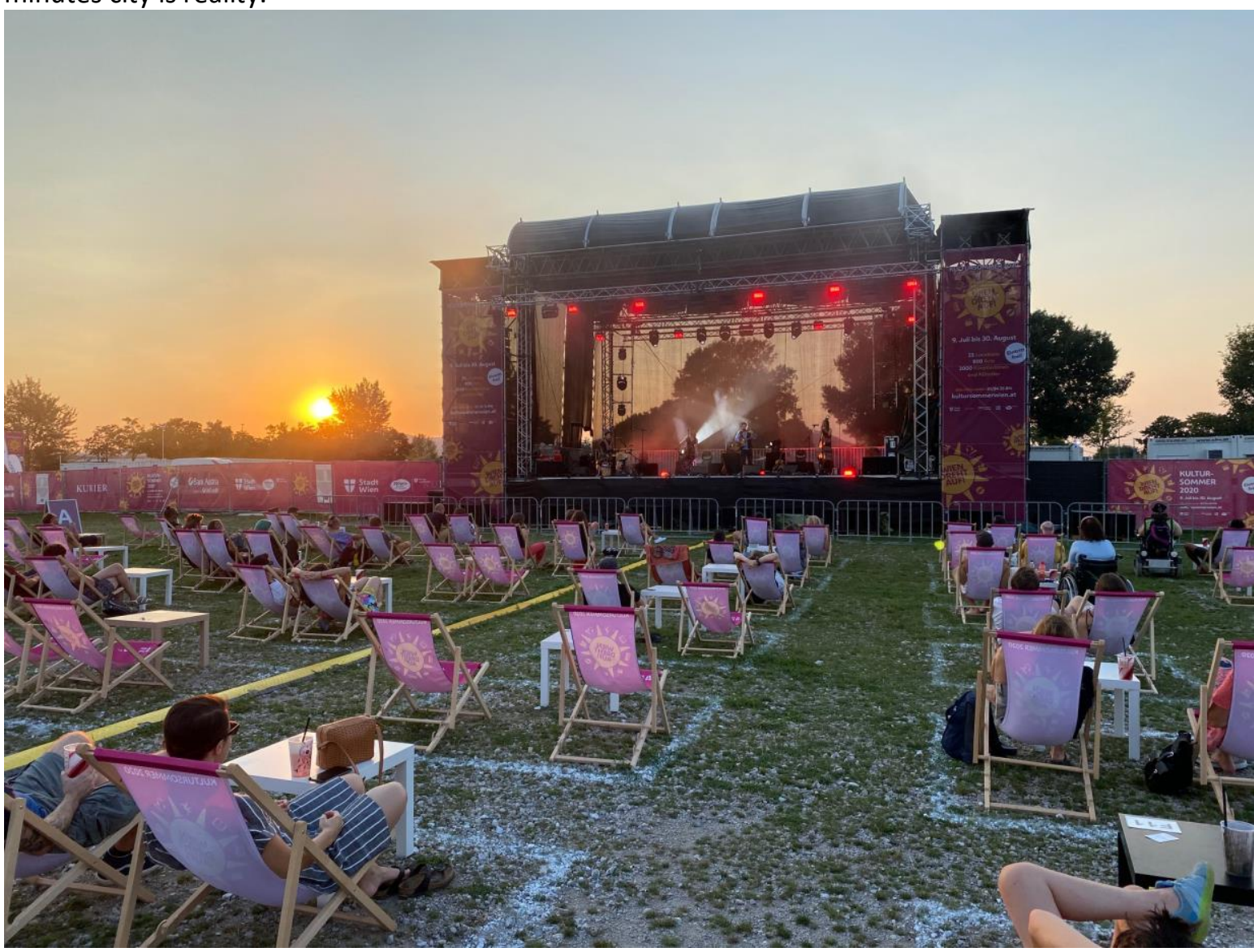

Fig.8 : Outdoor Summer Festival during the Pandemic - cultural events were decentralized in different parts of the city to prevent crowds, August 2020, Photo: S. Tillner

During the Covid-19 pandemic, the City of Vienna has intervened quickly by facilitating soft mobility and enlarging usable open spaces. Measures included the installation of pop-up bicycle lanes on streets without enough space for cyclists, the permission to walk on the driving lanes on narrow $2^{\text {nd }}$ category streets, eliminating on-street parking and allocating the space to outdoor seating for restaurants. The Vienna Festival, a highly popular and usually crowded 3-day open-air festival, which 
had to be cancelled due to the pandemic in May 2020 was transformed into a decentralized event in different neighbourhoods all-summer long in order to support the artists and offer cultural entertainment to the citizens in different parts of the city. A highly debated temporary intervention was a pop-up swimming pool in the centre of a street during summer. These measures were welcomed by the population, which has exceedingly started to use the open spaces for all kinds of activities and turned towards cycling in large numbers since March 2020. Whether these developments will become permanent remains to be seen.

\section{Research and Action Plan for Future Investigation}

The strategies and activities in both cities will serve as a starting point for future research; they will be collected, compared, and tested in terms of their applicability elsewhere.

In particular, concrete urban and architectural interventions either recently implemented or under way will be researched, categorized, evaluated, and exchanged. Based on the sharing of knowledge, a strategy consisting of guidelines, regulations and patterns that are applicable in both cities, address different aspects and are categorized accordingly will be formulated.

Using these guidelines as a base, several test cases will be developed, one for each category. They shall consequently be implemented concurrently and evaluated in regard to impact. Depending on the results, the measures shall receive broader application and become mainstream.

Documentation of this work will guarantee a larger audience and a broader impact.

\section{References}

1) Larsson A., (2020) Greenpeace Auckland, Thomson Reuters Foundation,

2) United Nations, Department of Economic and Social Affairs, 07/2020, Recover Better, https://www.un.org/development/desa/en/wp-content/uploads/2020/07/RECOVER BETTER 07221.pdf.

${ }^{3}$ Ghosh A. (2020) From promise to action: Sustainability at the heart of COVID-19 recovery, CEO, Council on Energy, Environment and Water, https://www.unenvironment.org/news-and-stories/speech/promiseaction-sustainability-heart-covid-19-recovery.

4) World Economic Forum COVID Action Platform.

4b) C40 Cities, www.c40.org; www.c40.my.salesforce.com.

5) Sala G. (2020) Mayor of Milan at the World Economic Forum, www.comune.milano.it.

6) Whittle N., (2020) Financial Times, FT weekend, ft.com , https://www.ft.com/content/c1a53744-90d54560-9e3f-17ce06aba69a.

7) Comune, (2020) Milano 2020. Strategia di adattamento, www.comune.milano.it.

${ }^{8)}$ https://www.c40reinventingcities.org/en/sites/sites-in-competition.

9) https://www.c40reinventingcities.org/en/events/reinventing-cities-finalists-2020-1437.html.

10) Écoquipe, contribution by Daniele Vettorato, EURAC.

11) https://www.comune.milano.it/aree-tematiche/partecipazione/milano-2020

12) Arvay C., (2020), Wir können es besser, Cologne, Germany, Quadriga

13) Fuchs P., Vienna City Admin. (2014) Smart City Wien Framework Strategy, Vienna, Austria 
